\title{
THE MOTION OF MARS 1751-1956
}

\section{By R. L. DUNGOMBE.}

Résumé. - Compte rendu du travail en cours à l'aide de la théorie du mouvement de Mars de Clemence.

Abstract. - Report on the work in progress using Clemence's theory of the motion of Mars.

Zusammenfassung. - Bericht über die im Gange befindliche Bearbeitung unter Benutzung der Theorie der Marsbewegung von Clemence.

Резюме. - Отчет о текущих работах в которых автор применяет теорию движения Марса Клеменса.

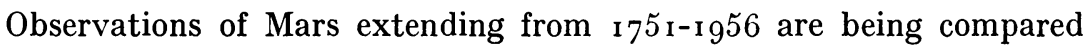
with an ephemeris based on Clemence's new theory of the motion of Mars (Astronomical Papers of the American Ephemeris, vol. 11, pt. 2 and vol. 16, pt. 2), in order to determine the definitive values of the constants of the theory. Approximately 5600 observations, comprising all the principal meridian transit series as well as the Cape heliometer measures, have been collected and referred to a common reference system. Clemence's theory of the motion of Mars has been evaluated for the time of each observation to form a geocentric ephemeris against which the observations have been compared.

The conditional equations comprise twenty five unknowns. They are corrections to six elements of Mars, eccentricity and perihelion of the Earth, the obliquity of the ecliptic, the equinox and equator point, the assumed scale of ephemeris time, and the mass of Venus as determined from perturbations produced in the orbits of Earth and Mars. Also introduced as unknowns are corrections to the secular variations of all the above quantities except the last.

Two different solutions of the normal equations yield the following provisional values of the reciprocal of the mass of Venus, $408762 \pm 468$ and 409 г $28 \pm 469$. 